\title{
The Relationship Between Trait Emotional Intelligence, Emotional Expressiveness, and Hopelessness Among Women Who Experience Domestic Violence
}

\author{
Lia Hervika ${ }^{1}$ Monty P. Satiadarma ${ }^{1 *}$ Naomi Soetikno ${ }^{1}$ \\ ${ }^{1}$ Faculty of Psychology, Universitas Tarumanagara, West Jakarta 11440, Indonesia \\ *Corresponding author. Email: montys@fpsi.untar.ac.id
}

\begin{abstract}
In Indonesia, cases of domestic violence rise every year with women having a higher prevalence being the victim. Victims may become hampered in reporting the case during current pandemic situation. Some studies reveal that domestic violence evoke psychological related-issues such as depression and suicide ideation. Previous study found that women who experience domestic violence report moderate to severe level of hopelessness. Trait emotional intelligence and emotional expressiveness seem play role toward hopelessness among victims. This study aimed to determine the correlation between trait emotional intelligence, emotional expressiveness, and hopelessness among 52 women who experience domestic violence in Indonesia. Nonexperimental quantitative research method with Pearson's correlational analysis is used to test the hypotheses. Measurement using the Beck Hopelessness Scale (BHS), the Trait Meta-Mood Scale (TMMS), and the Emotional Expressivity Scale (EES) with good reliability. Results show that trait emotional intelligence and hopelessness are negatively correlated, there is no correlation between emotional expressiveness and hopelessness, trait emotional intelligence positively correlated with emotional expressiveness. Trait emotional intelligence is more stable dispositional factor than emotional expressiveness and more significantly correlated to hopelessness among participants. Objectivity and specification of the violence among participants might be considered for further study. Social support and relationship quality may also be considered to study the emotional expressiveness among participants who experience domestic violence.
\end{abstract}

\section{Keywords: Hopelessness, domestic violence, trait emotional intelligence, emotional expressiveness}

\section{INTRODUCTION}

Violence against women in Indonesia increases $6 \%$ in 2019. National data reported 14.719 violence against women cases in Indonesia and $75 \%$ dominated by domestic violence [1]. Domestic violence is violent or aggressive behavior causes physical, psychological, and sexual suffering, including neglecting and manipulating in a domestic setting. The psychological impacts of domestic violence are suicidal ideation, suicide attempt, stress, sadness, and depression [2].

In Indonesia, domestic violence is considered as taboo, disgrace, and very personal problems. Victims are fear to open up about the violence. They tend to hide and obedient to the violence by their spouse. A study in Banten, Indonesia reveal that women aged 15-24 years old, have lower educational background, and living in rural area tend to admit the domestic violence issues. They see that men can use violence due to their right as a leader in family. This opinion is still adhered by people in patriarchy system.
Another reason victims did not report the violence is the limited understanding and knowledge about domestic violence and they do not know where to report [3].

Previous study reported that abused Turkesh women had moderate to high level of hopelessness. It describes that abused women who were over 40 years old, graduated from elementary school, were not working, had lowincome levels, and had no children reported a higher level of hopelessness. Abused women with high hopelessness show problem in making decisions and concentrating on a job. One of four domestic abused women in the study decide to return to their abusive partner. This decision also affected by cultural and social norm that marriage is sacred and must be preserved in any circumstances [4].

Another study, women in Midwestern town have different response toward abusive relationship with their partner [2]. Some participants reported still have motivation to change the violence cycle and meet their own needs. While other participants reported helplessness, self-blaming, and feel guilty to leave the abusive partner.

In Indonesia, one of three women who experience domestic violence indicates helplessness and suicidal ideation toward the experience [5]. Victim is afraid to 
oppose the abuser. However, victim decides to leave the abusive cycle in the relationship. While two other participants reported the violence to the family and file divorce even though it became harder for them to get a job. Overall, all the three participants show low selfesteem and fear to open up about the domestic violence experience.

Based on several studies, some women who experience domestic violence display hopeless responses. Hopelessness is a negative expectancy toward self and the future [5]. Hopeless individuals tend to lose motivation, have negative effects and expectancies toward the situation. They may also lose the ability in decision making [4]. The different level of hopelessness might be correlated with individual differences factors, such as emotional intelligence and emotional expressiveness. Abused women had lower emotional intelligence than nonabused counterpart. They display difficulties in recognizing and utilizing emotions that make the situation even worse with the abusive partner. Lower emotional intelligence impacts on ability to express emotions [7].

By expressing emotion, people assert their needs, feelings, and able to shape the environment. Previous study reveals that abused women who express emotions more, especially positive emotions, reported lower PTSD symptoms [8].

Expressing emotions also correlated to happiness and satisfaction in daily activities [9]. Apparently, individual factors such as trait emotional intelligence and emotional expressiveness are important for women who experience domestic violence. However, few evidence and study about hopelessness and its correlation with trait emotional intelligence and emotional expressiveness, especially related to domestic violence in Indonesia. This study aimed to determine correlation between hopelessness, trait emotional intelligence, and emotional expressiveness among women who experience domestic violence. We hypothesized that: (1) There are correlation between trait emotional intelligence and hopelessness, (2) correlation between emotional expressiveness and hopelessness, and (3) correlation between trait emotional intelligence and emotional expressiveness.

\subsection{Hopelessness}

Hopelessness defined by Beck et al [6] as 'a system of negative expectancies concerning himself and his future life'. Two components defining hopelessness are negative expectancies about the outcomes of the events and helplessness to change the negative outcomes [1]. Beck et al. [6] explain hopelessness in three aspects. First, affection aspect. Hopeless individuals have negative affect and are not happy about the future. Second, they lose motivation and helpless to change the negative outcomes. Third, cognition aspects. They see their future as dark, uncertain and cannot have a plan for future.

According to hopelessness theory of depression developed by Abramson et al. [10], hopelessness is a proximal sufficient factor for depression, especially hopelessness depression. It means that hopelessness is one of the factors close to depression. This theory also explains people tend to attribute their experience and have sense of importance about the experience. Tha attribution style were grouped in three dimensions, stable-unstable, global-specific, internalexternal. Those who see negative experience as stable, global, internal and see the experience as important for them are more likely to have higher hopelessness end up to hopelessness depression.

\subsection{Trait Emotional Intelligence}

Emotional intelligence according to Salovey et al. [11] is 'the subset of social intelligence that involves the ability to monitor one's own and other feelings and emotions, to discriminate among them, and to use this information to guide one's thinking and actions". Salovey et al. [11] explain emotional intelligence in two distinct term, trait and ability. EI as ability tend to see individuals' intelligence to master emotions in social context. EI as trait tend to see individuals' dispositional in experiencing their own emotions. Trait EI is more stable that Ability EI for individual in facing everyday life experience.

Trait EI describes individuals experiencing their own emotions by attending emotions (attention), recognizing emotions clearly (clarity), and able to repair negative emotions to be more positive (repair). Three dimensions describing trait EI are attention refers to which individuals pay attention, think about their emotions, and likely to see their emotions as important. Clarity refers to which individuals understand and know their emotions clearly. Individuals who clear about their emotions able to tell what are they feeling. Repair refers to the ability to regulate negative emotions to be more positive in a socially accepted way. Individuals with higher trait emotional intelligence able to cope with emotional burdens before they make further decision about the problem [12]. Emotionally intelligence individuals also show more adaptive attribution style and optimism in coping with negative life events [12].

\subsection{Emotional Expressiveness}

Emotional expressiveness is defined by Kring et al. [13] as 'the outward of display of emotion, regardless of valence (positive or negative) or channel (facial, vocal, or gesture). According to the definition, emotional expressiveness describes dispositional tendency for individuals to show their emotions outwardly. Those who expressing their emotional don't mind if other people know how and what they are feeling. Previous study show that emotional expressiveness associated with positive affection, happiness, and satisfaction in daily activities [9]. 


\section{METHOD}

\subsection{Participants}

Data were collected by both offline and online questionnaire. 94 data were collected and screened by the domestic violence criteria checklist, such as physically abused, psychologically abused, sexually abused, and economic abuse. Participants who never have experienced domestic violence were excluded, so the total participants that included in this study are 51 women who experience domestic violence. Age of participants were 20-40 years old $(86.3 \%)$; $40-60$ years old $(13.7 \%)$. Participants were working (74.5\%\%); high school level education background (31.4\%); divorced (56.9\%); have not experienced abused anymore $(74.5 \%)$. The violences were physically (21.6\%); psychologically (21.6\%); financially $(5.9 \%)$. Others reported have experienced more than one dimension of violence. $49 \%$ data were collected offline. Participants were screened at the first section of the questionnaire. After fill the biodata, participants were asked if they (a) still experiencing domestic violence, (b) have not experienced anymore, and (c) never experienced domestic violence. Participants that have never experienced domestic violence were directed to the closing section. For more information and confirm about the violence, participants were asked to fill the checklist about what kind violence they experienced. There were five checkboxes, such as (1) physical violence (action causes illness or injury physically), (2) psychological (insulting, threatening, condescension or any action causes mental suffering), (3) sexually (violence or forced sexual activity), (4) financially (neglect, manipulating). Participants also asked if they report the domestic violence to the local institution and telling their experience to relatives or family. They also allowed to ask any research related question by personal WhatsApp chat.

\subsection{Measurement}

Data were collected using Beck Hopelessness Scale (BHS) by Beck et al. [6] that translated into Bahasa Indonesia. BHS also used in previous study Kisa et al. to determine the hopelessness level in abused women in Turkey [4]. In this study the Cronbach's alpha reliability coefficient of the 15 items is 0.720. Participants have two choices to response the items 'Agree' scored 1 and 'Disagree' scored 0 . The higher score of the participants indicates higher hopelessness. Trait emotional intelligence is measured by Trait Meta-Mood Scale (TMMS) by Salovey et al. [11] that translated into Bahasa Indonesia. In this study, the Cronbach's alpha coefficient for 18 items is 0.85. TMMS also measure the three dimensions. Attention (TMMS-A) is represented by 8 items; Clarity (TMMS-C) is represented by 5 items; and Repair is represented by 5 items. Each item scored by Likert scale from $1=$ strongly disagree to $5=$ strongly agree. The higher score of TMMS indicates higher trait emotional intelligence of the participants. Emotional expressiveness is measured by Emotional Expressivity Scale (EES) by Kring et al. [13] that translated to Bahasa Indonesia. In this study, the Cronbach's alpha coefficient for 16 items is 0.881 . The higher score of EES indicate the higher emotional expressiveness of the participants.

\subsection{Research design and procedure}

This is non-experimental quantitative study to determine correlation between variables among participants. Measurement tools were translated to Bahasa Indonesia and tested to married women in Indonesia. Participant recruited by research announcement via social media. Announcement including participant criteria and questionnaire link. Data were also collected offline in a working circle in Pangkalpinang.

Statistical analysis using SPSS v.21. Normality data distribution and measurement reliability were also tested in this study. Pearson correlation analysis was used to tested the correlation between variables. Variables differences also analyzed using Independent Sample t-test and Oneway ANOVA.

\section{RESULTS}

Table 1 shows Pearson correlation of the variables. Results show that trait emotional intelligence negatively correlated to hopelessness $(r=-0.474, p<0.01)$. Participants that have higher score of trait emotional intelligence have lower score of hopelessness. Likewise, higher score of hopelessness shows lower score of trait emotional intelligence. Three dimensions of trait emotional intelligence also negatively correlated to hopelessness. Attention (TMMS-A) negatively correlated to hopelessness, $(r=-0.293 ; p<0.05)$. Clarity (TMMS-C) negatively correlated with to hopelessness, $r=-0.432$; $p<0.05$. Repair (TMMS-R) negatively correlated to hopelessness, $r=-0.444 ; p<0.05$.

Result shows there is no correlation between emotional expressiveness and hopelessness among participants. Meanwhile, emotional expressiveness positively correlated to trait emotional intelligence $(r=0.521 ; p<0.05)$. Attention $(r=0.38 ; p<0.05)$ and clarity $(r=0.517 ; p<0.05)$ positively correlated to emotional expressiveness. While repair have no correlation to emotional expressiveness.

This study found woman who experience three kinds of violence (psychological, sexual, and financial) had the highest score of hopelessness (hopelessness score $=11$ ) . Those who report the case to the local institutions show lower level of hopelessness $(\mathrm{t}=-3.677, p<0.05)$.

Women with higher level of educational background had higher trait intelligence $(\mathrm{F}=3.527 ; p<0.05)$ and more expressive $\quad(\mathrm{F}=7.106 ; \quad p<0.05$. Offline recruited participants show higher emotional expressiveness than online recruited participants $(\mathrm{t}=2.214, p<0.05)$. 
Table 1 Pearson's correlation matrix of the variables

\begin{tabular}{lcccccc}
\hline Variables & $\mathbf{1}$ & $\mathbf{2}$ & $\mathbf{3}$ & $\mathbf{4}$ & $\mathbf{5}$ & $\mathbf{6}$ \\
\hline 1.BHS & 1 & & & & & \\
2.EES & -0.270 & 1 & & & & \\
3.TMMS & $-0.475^{* *}$ & $0.532^{* *}$ & 1 & & & \\
4.TMMS-A & $-0.296^{*}$ & $0.446^{* *}$ & $0.801^{* *}$ & 1 & & \\
& & & & & \\
5.TMMS-C & $-0.432^{* *}$ & $0.530^{* *}$ & $0.857^{* *}$ & $0.456^{* *}$ & 1 & \\
6.TMMS-R & $-0.446^{* *}$ & 0.233 & $0.725^{* *}$ & $0.339^{*}$ & $0.583^{* *}$ & 1 \\
\hline$* *)$ correlation is significant at the 0.01 level (2-tailed) & & & \\
*) correlation is significant at the 0.05 level (2-tailed) & & &
\end{tabular}

\section{DISCUSSION}

In this study, we determine correlation between hopelessness, trait emotional intelligence, and emotional expressiveness among domestic abused women. Results show that hypotheses 1,3 , and 4 were supported but not hypothesis 2 . First, trait emotional intelligence negatively correlated to hopelessness among domestic abused women. Those who attending, recognizing, and repairing negative emotions show lower hopelessness. According to Gohm and Clore [12], Miri [14], Tsirigotis and Luczak [7], Noorbakhsh [15], Zou and Chen [16], those who higher in trait emotional intelligence able to cope and have adaptive attribution to negative life events and likely showing lower-level impacts of domestic violence. Participants that show lower level of hopelessness tend to attend their emotions, recognizing emotions clearly, and able to repair negative emotions to be more positive.

Second, emotional expressiveness is not correlated to hopelessness among participants. According to Clark and Finkel [17], expressing one's emotions will benefit if people perceived the relationship was supportive and communal. Perceived social support and the relationship quality may play role in correlation between expressing emotions and hopelessness among domestic abused women.

Third, Trait emotional intelligence and emotional expressiveness positively correlated among participants. This finding support Gohm and Clore 12] that those who experience their emotions thend to able express their emotions. However, emotional repair is not correlated to the emotional expressiveness. Kobylinska and Kusey [18] found that people can adaptively regulate or control their overwhelming emotions by flexible emotional regulation, including expression suppressions. It shows that those who emotionally intelligent not always express but also suppress their emotions according to the situations.

Fourth, comparing the individual factors, trait emotional intelligence shows more significant and negative correlation to hopelessness. It shows that emotional intelligence is more stable in individual, while emotional expressiveness might be more depends on cultural context. East culture seems more supress strategy in expressing valence (positive or negative) and channel (verbal or nonverbal) of the emotions.

Over all, half participants reported low to moderate level of hopelessness. Participants dominated by those who no longer experienced violence, working, and separated from the abuser. Consistent with Deborah [5] that participants decide to leave the abusive partner and work to be financially independent. Kisa et al. [4] also reveal that those who were working, plan to start a new life, and find a job tend to had lower hopelessness.

Participants with higher level educational background had higher level of trait emotional intelligence and higher emotional expressiveness. This finding reveals that higher education helps individuals in experiencing emotions and expressing their emotions.

Result also found that participants that recruited offline had higher emotional expressiveness than online recruited participants. Offline participants live in urban area in Pangkalpinang. Data shows that participants in Pangkalpinang decide to leave and get a job even though domestic violence is still something taboo and personal problem. They may difficult to hide their marriage status and violence experience in working environment. They also share and know each other about the violence experience. Consistent to Clark and Finkel [17] that individuals tend to express their emotions in the supportive and communal relationship.

There are some limitations of this study. First, 74,5\% participants have not experienced domestic violence anymore, separated from abusive partner, and financially independent. That might impact participant's level of hopelessness and not representative for women who are still experiencing domestic violence. Further study may only recruit participants who still experiencing domestic violence in current situation. Second, emotional expressiveness is not specifically measured. That might be impact the relationship between emotional expressiveness and hopelessness among participants. Further study may specify the emotions that want to be measured and to whom participant express their emotions. Third, generalization of the results is limited. Nearly half of the participants were from Pangkalpinang. Participants in Pangkalpinang and out of Pangkalpinang may differ from cultural view and social consequences about domestic violence and divorce. Further study may consider more participant with different cultural background.

\section{CONCLUSION}

Earlier studies have found several impacts on domestic abused women including hopelessness. This study found 
that trait emotional intelligence is one of the individual factors correlated with hopelessness among domestic abused women. Those who attend to emotions, recognize emotions clearly, and able to repair negative emotion to be more positive tend to show lower hopelessness. However, emotional expressiveness is not correlated to hopelessness in this study. Further study about emotional expressiveness among women who experience domestic violence may consider perceived social support and the quality of the relationship to whom they express their emotions. This is the first study that including domestic violence victims in Pangkalpinang and some regions in Indonesia using both offline and online questionnaire. The results of this study may trigger more exploration about emotional intelligence and emotional expressiveness among domestic abused women. By this study, professionals may also find that is quite important for women who experience domestic violence to develop trait emotional intelligence.

\section{ACKNOWLEDGMENT}

Acknowledgement and words of gratitude are addressed towards Faculty of Psychology Universitas Tarumanagara for their support and opportunity given to us.

\section{REFERENCES}

[1] Komisi Nasional Anti Kekerasan Tehadap Perempuan, Kekerasan meningkat: Kebijakan penghapusan kekerasan seksual untuk membangun ruang aman bagi perempuan dan anak perempuan. Catatan Tahunan Tentang Kekerasan terhadap perempuan tahun 2019 (2020)

[2] G. Karakurt, D. Smith, J. Whiting, Impact of intimate partner violence on women's mental health. J Fam Violence 29(7) (2014) 693-702. DOI: 10.1007/ s10896-014-9633-2

[3] F. Fajrini, R. A. Ariasih, N. A. Latifah, Determinan sikap terhadap kekerasan dalam rumah tangga di Provinsi Banten, Aspirasi: Jurnal Masalah-Masalah Sosial 9(2) (2018) 173-189. DOI: https://doi.org/10. 22212/aspirasi.v7i1.1084

[4] S. Kisa, S. Zeyneloglu, E. S. Verim, The level of hopelessness and psychological distress among abused women in a women's shelter in Turkey. Archives of Psychiatric Nursing 33(1) (2018) 30-36. DOI: https://doi.org/10.1016/j.apnu.2018.08.009

[5] S. Deborah, A. Muthmainnah, L. Herlinda, S. S. Tanawi, Trauma dan resiliensi pada wanita penyintas kekerasan dalam rumah tangga. Jurnal Ilmiah Psikologi MANASA 7(2) (2018) 121-130.

[6] A. T. Beck, A. Weissman, D. Lester, L. Trexler, The measurement of pessimism: The hopelessness scale. Journal of Consulting and Clinical Psychology 42(6) (1974) 861-865

[7] K. Tsirigotis, J. Łuczak, Emotional intelligence of women who experience domestic violence. Psychiatr Q, 87 (2016) 165-176. DOI: 10.1007/s11126-015-9368-0

[8] T. J. Sullivan, F. R. Leifker, A. D. Marshall, Observed emotional expressivity, posttraumatic stress disorder symptoms, and intimate partner violence perpetrationamong community couples. Journal of Traumatic Stress, 00 (2018) 1-10. Doi: 10.1002/jts

[9] C. J. Burgin, L. H. Brown, A. Royal, P. J Silvia, N. Barrantes-Vidal, T. R. Kwapil. Being with others and feeling happy: Emotional expressivity in everyday life. Per Individ Dif. 53(3) (2012) 185-190. DOI: 10.1016/j.paid.2012.03.006.

[10] L. Y. Abramson, G. I. Metalsky, L. B. Alloy, Hopelessness depression: A theory-based subtype of depression, Psychological Review 2(96) (1989) 358372

[11] P. Salovey, J. D. Mayer, S. L. Goldman, C. Turvey, T. P. Palfai, Emotional attention, clarity, and repair: Exploring emotional intelligence using the Trait Meta-Mood Scale, in: J. W. Pennebaker (Ed.) Emotions, Disclosure, and Health, Washington, D. C: American Psychological Assn, 1995

[12] C. L. Gohm, G. L. Clore, Four latent traits of emotional experience and their involvement in wellbeing, coping, and attributional style. Cognition and Emotion 16(4) (2002) 495-518. DOI: $10.1080 / 02699930143000374$

[13] A. M. Kring, D. A. Smith, J. M. Neale, Individual differences in dispositional expressiveness: Development and validation of the emotional expressivity scale. Journal of Personality and Social Psychology, 66(5) (1994) 934-949

[14] M. R. Miri, T. Kermani, H. Khoshbakht, M. Moodi, The relationship between emotional intelligence and academic stress in students of medical sciences. Journal of education and health promotion, 2(40) (2013). DOI: https://doi.org/10.4103/2277-9531.115836

[15] S. N. Noorbakhsh, M. A. Besharat, J. Zarei, Emotional intelligence and coping style with stress. 
Procedia Social and Behavioral Sciences 5 (2010) 818822. DOI: 10.1016

[16] L. Zhou, J. Chen, Life events and hopelessness depression: The influence of affective experience. PLoS ONE 12(1) (2017). DOI: https://doi.org/10.1371/ journal.pone. 0187898

[17] M. Clark, E. J. Finkel, Willingness to express emotion: The impact of relationship type, communal orientation, and their interaction, Personal Relationships 12(2) (2005) 169-180.DOI: 10.1111/j.1350-4126.2005. 00109.x

[18] D. Kobylinska, P. Kusev, Flexible emotion regulation: How situational demands and individual differences influence the effectiveness of regulatory strategies. Front Psychol 10(72) (2019) 